\title{
Mapping the Five Contributions onto the Ontological and Axiological Dimensions of the Emerging Responsible Innovation Paradigm. An Introduction to the Special Issue on Responsible Innovation
}

\section{Job Timmermans ${ }^{1}$}

Published online: 13 August 2020

(C) Springer Nature Switzerland AG 2020

\begin{abstract}
This is the introduction to the special issue on Responsible innovation (RI). The special issue presents five philosophical analyses into the foundational concepts and assumptions of RI. This paper explores the common themes that emerge across these five analyses by mapping them onto the ontological and axiological dimensions of the newly emerging RI paradigm. This way, we are able to articulate the (known) shortcomings of RI as well as the possible way forward suggested by the authors to remedy them.
\end{abstract}

Keywords Responsible innovation $\cdot$ Ontology $\cdot$ Axiology $\cdot$ Paradigm shift

Responsible Innovation (RI) is an emerging concept to consider ethical and social aspects during innovation processes. This will lead to innovations that are socially desirable and ethically acceptable (Sutcliffe 2011; Von Schomberg 2013), in juxtaposition with the more traditional objectives of innovation like economic growth, profit maximization, competitive advantage etc. Because the concept of responsible innovation is relatively new and still evolving in different directions (Cf. Owen et al. 2013; van den Hoven et al. 2014), there are several under-researched areas. One of them is the philosophical underpinning of the concept of innovation and related concepts in the field of responsible innovation (Blok and Lemmens 2015; Timmermans and Blok 2018).

Targeting this gap, a dedicated special issue of the Philosophy of Management journal presents the philosophical analyses of six different authors into the foundational concepts and assumptions of RI. In this introduction to the special issue, we briefly summarize and explore the (common) themes that emerge across these five analyses. This way, we are able to articulate some of the (known) shortcomings of RI as well as the possible way forward

Job Timmermans

jfc.timmermans@mindef.nl

1 Faculty of Military Sciences, Netherlands Defence Academy, Breda, Netherlands 
suggested by the authors to remedy them. To do so we will first introduce a basic framework (first introduced in Timmermans and Blok 2018) that allows us to arrange the contributions to this special issue according to their paradigmatic angle they deploy to critique RI.

At a fundamental level, the emergence of RI can be understood as a paradigm shift that addresses the (apparent) anomalies of the prevalent techno-economic or 'classic' innovation paradigm. This shift can be analysed in terms of two basic elements of paradigms: ontology and axiology. ${ }^{1}$ Ontology refers to basic assumptions about reality, epistemology entails the nature and origin of knowledge while axiology concerns that which is of value or worthwhile (Given 2008, p. 593; Morgan 2007).

In terms of ontology, different conceptualizations of RI as an alternative paradigm then suggest a new way of understanding innovation and introduce the concept of responsibility as its necessary counterpart. In terms of axiology, the alternative paradigm includes alternative ways of valuating innovations and innovation processes based on stakeholder/ public participation and ethics.

Although the different conceptualizations of RI aspire changes that have repercussions on a fundamental level, this paradigm shift is not explicitly addressed by the literature on RI. Rather, in most cases the implied fundamental changes are implicitly assumed and as a result, remain understated and underdeveloped. Moreover, when analysing the current conceptualizations of RI on a paradigm level, tensions were unveiled both between the different conceptualizations and between RI and the classic innovation paradigm more in general (Timmermans and Blok 2018). Strengthening RI as a viable alternative to the classic innovation paradigm would therefore require critically engaging with these suggested fundamental changes on both paradigmatic elements.

The five papers of this special issue can be understood to do just this. By mapping the papers against the two basic paradigm elements, we can articulate where and how the papers engage in a dialogue with the RI discourse concerning its (implicit) foundational assumptions. Below, each paper is briefly introduced and then discussed from an ontological and axiological perspective.

\section{Daniele Ruggiu}

The aim of the paper by Ruggiu (2020) is to strengthen the normative foundation of RI in order to make it more effective to put into practice. To this end, the author addresses a fundamental tension that lies at the heart of RI. The literature on RI tends to be polarised around two ways of grounding morality, namely: a socio-empirical approach that is geared towards inclusion vs. a normative approach that is geared towards ethical acceptability. Subsequently, each leads to a different viewpoint of what the meaning of responsibility should be: care for the future (Grinbaum and Groves 2013) and respect for fundamental ethical principles (Von Schomberg 2013). By analysing the opposing frameworks, the author aims to contribute to better understand this tension between ethics of care and ethics of rights, and ultimately to resolve it. While the ethics of care is strongly tied in with the newly emerging RI paradigm, the ethics

\footnotetext{
${ }^{1}$ It is common in social science methodology to also distinguish epistemological and methodological assumptions of paradigms. However, we limit ourselves here to ontological and axiological assumptions. The reason is that ontological and axiological assumptions support the investigation of the perception, understanding and valuation of (social) reality in a practical domain such as innovation, while methodological and epistemological assumptions are more relevant in case a particular scientific discipline is involved (See, e.g. Fagerberg et al. 2013).
} 
of rights is being associated with the classic innovation paradigm i.e. the individualistic, neoliberal model of justice. Ruggiu shows how the tension not only resides between the classic and newly emerging paradigm but also within the newly emerging paradigm, between the (seemingly) opposing pulls towards ethics and inclusivity. Ultimately, the author argues how this tension can be resolved by balancing care ethics with an evolved version of right ethics, called hermeneutic right ethics.

From an ontological perspective, the paper shows that RI suffers from a 'conceptual indeterminacy'. RI encompasses a multitude of different ethical frameworks that coexist within the same moral horizon but lead to different meanings of responsibility. Most pressing this tension is expressed in the fundamental tension between inclusion and ethical justification. In addressing this tension, the ontological perspective is thus inseparably tied together with the axiological perspective, where the centre of the gravity of the paper resides.

Axiologically, RI can be understood to offer an alternative to the classic valuation of innovation. This new valuation necessary brings along a novel way of understanding and hence of conducting innovation. An important strand in this paradigm shift is the plea for care ethics as an alternative to the consequentialist and rights-based ethics of the classic innovation paradigm. Ruggiu argues, however, that such a one-sided abandonment of the classic paradigm is not justified. Despite its explicit aim at stakeholders' needs, care ethics omits the inclusion of the needs of all stakeholders thereby 'weakening the responsibility framework'. By reintroducing an amended (hermeneutic) rights perspective, this weakness of care ethics can be remedied. Rather than merely proposing a return to the classic paradigm, this new version of rights ethics is brought forward as compatible and complementary to care ethics. As such it may function as a bridge between the socio-empirical approach and normative approach, thereby, resolving the tension.

\section{Agata Gurzawska}

Going beyond the question of why responsibility should be implemented, the paper by Gurzawska (2020) revolves around the question of how to implement responsibility effectively in a particular field, in this case, supply chain management (SCM). When implemented effectively this will lead to responsible supply chain governance. Although not addressing RI directly, the question of how to manage supply chains in a responsible manner is of great merit for the RI discourse.

Similar to RI, Responsible Supply Chain Governance (RSCG) ties in with the (recent) use of the term responsibility to depict a turn towards including ethical and societal values and/or sustainability, most notably in the field of Corporate Social Responsibility (CSR). As argued before, this turn can be understood to represent a paradigm shift under the common denominator 'responsibility'. This paradigm shift responds to the anomalies that arose under the previous, classic paradigm, in which fields were guided by market-forces and only steered ex-ante via regulation and legislation, by including governance based on societal and ethical values through the engagement with and inclusion of stakeholders and the general public (Cf. Grunwald 2011; Pellizzoni 2004). In both RI and RSCG, the introduction of the notion of responsibility can be viewed as an answer to the complexities and uncertainties, partly due to societal demands, that have arisen over the last decades. Apart from these shared interests such as how to manage responsibility, focussing on RSCG also is of value to understanding RI by the contrast it offers due to the differences between the two fields of application. This will allow us to better understand the particularities that are specific to introducing responsibility into the field of innovation. 
Whereas the other four papers of this SI take a top-down approach, i.e. a conceptual discussion of the core concepts and assumptions behind them, Gurzawska's paper approaches the concepts bottom-up by starting from a specific case from a particular context and field. This allows us to think through the specific demands to responsibility when such a concept is being introduced into a particular field or domain. The paper thus highlights potential issues that may be encountered and goes on to discuss how these can be dealt with. By taking this alternative approach, the paper arrives at a paradigmatic position that is similar to that aspired by RI. However, rather than arriving there through rational argumentation only, as do the other four papers, Gurzawska offers empirical evidence to ground this position.

From an ontological perspective, the paper starts from the notion that a vacuum of responsibility exists due to complexity and uncertainty. This vacuum needs to be addressed by introducing a new, dedicated notion of responsibility that includes supra-agent responsibility and enables dealing with multi-stakeholder networks. Supra-agency takes the form of coalitions of non-state actors which codify, monitor, and in some cases certify firms' compliance with labour, environmental, human rights, or other standards of accountability.

From an axiological perspective, the implies that innovation has inherent value as a contributor in dealing with uncertainty and complexity. Innovation has the potential to sustain the enhancement of positive and reduction of negative societal and environmental consequences. But to realize this potential, and in line with RI, valuation needs to take place in the (socio-) political and ethical spheres through the introduction of new governance models that support inclusivity and normative anchor points.

\section{Harald Stelzer}

In his critical contribution, Stelzer (2020) challenges some of the foundational assumptions of RI with regard to participation, inclusiveness and responsiveness. Arguably, these assumptions have been articulated most clearly through the four dimensions of the RI framework posited by Stilgoe et al. (2013). In their paper, Stilgoe et al. use Climate Engineering as a founding case (the SPICE project) to ground their RI framework. Boldly, Stelzer uses the same case to illustrate his argument pointing in the opposite direction. Contrary to Stilgoe et al., Stelzer concludes that the failure of the SPICE project shows that the participatory turn in RI may cause some setbacks for research as well as for our evaluation of different options. Opening up the debate to the general public, therefore, should not be the default option to valuate innovation processes. On the contrary, when innovation is (still) fraud with uncertainty and there are deeper conflicts of interest or differences in underlying values, norms and principles, closing down would be the preferred mode of operation. Engaging stakeholders may not be able to overcome the conflicts and differences especially under a lack of information. Rather, returning to Technology Assessment (TA) (of which RI partly emanated) and its early warning-function, is better suited for innovation under these circumstances.

Ontologically, Stelzer questions the conceptualization of responsibility in terms of responsiveness and inclusion. Central is his analysis is the question who ought to be the subject of responsibility in relation to the object of a particular innovation when it is surrounded by epistemic and normative uncertainty. Rather than widening the range of subjects to include the wider stakeholders foremost the general public, Stelzer argues to 'take a step back to TA' and retain or limit the scope to ethicists and experts from other disciplines. 
From an axiological perspective, the conceptualization of responsibility within the newly emerging RI paradigm is then criticized for harnessing the general public as a legitimate source of normative valuation of innovation. The call for democratizing and opening up the debate and engage wider audiences finds its legitimacy in the need to include marginalised perspectives, neglected issues, ignored uncertainties and alternative options. However, despite the importance of including such additional sources of information, Stelzer argues, this may give rise to deep conflicts of interests, which in turn will hamper the decision-making process. Moreover, it is not at all clear how engaging stakeholders such as the general public helps in overcoming such conflicts and differences. Conversely, closing down aims at cutting through the messy, intractable and conflict-prone diversity of views in order to develop prescriptive recommendations to assist in decision-making. TA supports this process by identifying the salient viewpoints, finding the priority issues, and highlighting the most likely outcomes. Rather than the general public, by deploying TA, experts will constitute the legitimate source (or at least the channel) of normative valuation.

\section{Hans Bennink}

In his paper, Bennink (2020) carves out an underlying pattern in the literature on RI that will help to bring the discourse to the next stage of fruition. Taking the current lack of conceptual clarity surrounding RI as a starting point, the paper begins by critically discussing the meaning of the basic underlying concepts of responsibility and innovation and their relationships. It then goes on to explore the linguistic ambiguity of the concept of innovation drawing on a management/organizational perspective of innovation. Based on this, common moral themes in innovation are identified and discussed in terms of five tensions. These are subsequently arranged into five spearheads for the theory, research, and practice of RI as possible steps towards bringing the discourse to the next stage in its evolution as a construct.

From an ontological perspective, the paper thus seeks to support RI's aspired paradigm shift by offering pathways that enable further clarification on the concepts of responsibility and innovation and their interrelationships. To this end, guiding questions are posed that need addressing by the discourse concerning particular instances of innovation, such as what the exactly is the object of innovation and who makes up the subjects of responsibility, and what norms should be applied to assess the innovation at hand? Answering these questions provides a context in which the moral aspects of innovation can be considered.

Axiologically, the paper articulates as its anthropological departure point, which surpasses the limited economic perspective in sway under the classic paradigm, that innovation is an important element of the human condition. Innovation thus is perceived as a means to improve that condition, even by solving existential problems, but also may pose a threat to it, for instance, oppressing humanity or leading to planetary destruction. Based on this, the paper identifies five interrelated fields of tension that are essential to innovation and each has its own moral issues and areas of responsibility:

1. to innovate or not to innovate, in terms of motives, purposes, objectives, resistances,

2. the degree of innovation: from minor improvement via incremental to radical (breakthrough/disruptive),

3. the range of innovation themes: single or effective bundles,

4. innovation with whom: alone or together (partnership/open innovation/co-creation), and 
5. the innovation process and organizational institutionalization of innovation (incidental or routine).

To address these tensions effectively, Bennink makes a case for the proliferation of moral and ethical expertise among the actors involved in RI.

\section{Johann Jacob Häußermann \& Fabian Schroth}

In their paper, Häußermann and Schroth (2020) scrutinize RI's critique of the market-mechanism as a primary means to govern innovation trajectory as well as its proposing of participatory governance as a substitute. Similar to Ruggiu and Stelzer, the authors argue that this departure from the classic paradigm is too rigorous. Instead of abandoning the individualist approach of the classic (economic) paradigm, as RI theorists suggest, most prominently by Von Schomberg (2013), Häußermann and Schroth propose to shift the boundaries of the classic paradigm by further developing the individualist approach based on preference learning. This allows to include individuals not just as consumers but as co-innovators thereby enhancing participation and inclusivity. To put this alternative into practice the paper concludes by developing the notion of Laboratories in a realworld context (LRW). An LRW provides an appropriate institutional and methodological framework that helps individuals to develop ethical preferences for the (future) development of R\&I. This resonates strongly with a social lab methodology aimed at implementing RI based on experiential and mutual learning that was proposed by Timmermans et al. (2020).

Ontologically, Häußermann and Schroth target the understanding of responsibility presupposed in the newly emerging paradigm, more in particular, the subjacent concept of participation. Similar to Stelzer, they criticize the broadening of the subject of responsibility under the emerging RI paradigm i.e. by replacing individual consumers under the market mechanism with the general public through participation. As an alternative, the authors adopt a middle course that enhances the concept of participation by recovering the role of the individual, not as a consumer but as a co-innovator.

From an axiological perspective, this entails that the valuation of innovation does not just take place via stakeholders such as the general public or via the market as was the case under the classic paradigm. Instead, an alternative normative economic approach is proposed based on preference learning. This entails a departure of conventional welfare economics, which regards the satisfaction of individual preferences as revealed in peoples' choices as a sole normative criterion. Thereby, it relies on neoclassical assumptions of rationality, according to which people have stable and coherent preferences. This problem of assuming the existence of "true" or latent preferences is circumvented by changing the role and normative status of single preferences to outcomes of an ongoing process of learning. So, by focussing on the process of preference learning not only the participatory dimension of responsible innovation is taken seriously, but it also enhances our understanding of the concept by providing a new perspective on the role of the individual.

\section{Conclusion}

All authors of this special issue (critically) discuss fundamental assumptions that lie at the core of RI. In this way, they contribute to strengthening the foundation of RI and with it, its implementation into, and hence, impact on innovation practices. Not only do the discussions help to make a stronger 
argument for RI, three of the contributions argue against a radical departure of classic innovation paradigm's assumptions as proposed by some of the conceptions of RI. Instead, they suggest a partial return to the classic paradigm by to salvage its more advantageous characteristics that otherwise would have been lost under the newly emerging RI paradigm. Opting for a closer alignment with the classic paradigm helps to increase the success of RI. Holding on to what is known and accepted by the those the R\&I community lowers the barrier to the uptake of RI by that community. So, by challenging the core assumptions of RI and offering a middle road, the papers help RI to realize its aspirations.

From an ontological perspective, all five the papers take aim at the concept of responsibility and how it is currently understood by the RI discourse. The papers discuss the subject and object of responsibility that is being assumed by conceptualizations of RI, as well at the relationship of responsibility with other core notions. Ruggiu, Stelzer and Häußermann and Schroth, for example, question the broadening of the subject proposed by RI, while Bennink and Gurzawska scrutinize the relationship between responsibility and innovation. These discussions of the subject and object of responsibility tie in closely with consideration for the moral dimension of responsibility.

From an axiological angle, three authors do so by critiquing RI's normative foundation, namely care ethics (Ruggiu) and the general public as a source of normative valuation (Stelzer and Häußermann \& Schroth). All three these authors argue that RI has been too rigorous in burning its bridges and suggest a re-valuation of its precursors, namely individual (human) rights (Ruggiu), Technology Assessment (Stelzer) and the market (Häußermann \& Schroth). On a more practical note, Gurzawska discusses the inherent value of innovation as a potential contributing factor in dealing with uncertainty and complexity. Providing that innovation is properly governed, it is therefore not merely an object of responsibility but also indispensable for taking or discharging responsibility. Finally, Bennink takes a more holistic approach by identifying five interrelated fields of tension that are essential to innovation and each has its moral issues and areas of responsibility.

By critically engaging with RI's core assumptions and some of the tensions they raise, the five contributions to this special issue pave the way forward in reflecting and reinforcing the foundations of RI. The papers not only provide a substantial contribution to the discourse, but they also set an example on how to engage critically with RI's core assumptions: top-down through a conceptual discussion or bottom-up by operationalizing the concepts in a particular practical domain. This is of key importance because a lot of ground remains untouched (Cf. Timmermans and Blok 2018). Moreover, as the follow-up questions raised by the papers show, reflection necessarily entails opening up new horizons in need of exploration. We therefore sincerely hope that this special issue provides an incentive and encouragement to scholars within (or outside) the RI discourse to participate in the discussion on RI's fundamental concepts and assumptions.

\section{Compliance with Ethical Standards}

Conflict of Interest The author states that there is no conflict of interest.

\section{References}

Bennink, H. 2020. Understanding and managing responsible innovation. Philosophy of Management 19 (3). https://doi.org/10.1007/s40926-020-00130-4.

Blok, V., \& Lemmens, P. (2015). The emerging concept of responsible innovation. Three reasons why it is questionable and calls for a radical transformation of the concept of innovation. In B.-J. Koops, I. 
Oosterlaken, H. Romijn, T. Swierstra, \& J. van den Hoven (Eds.), Responsible Innovation 2 (pp. 19-35). Springer International Publishing. http://link.springer.com/10.1007/978-3-319-17308-5_2

Fagerberg, J., Martin, B. R., \& Andersen, E. S. (Eds.). (2013). Innovation studies: Evolution and future challenges (1st ed). Oxford University Press.

Given, L. M. (2008). The SAGE encyclopedia of qualitative research methods. SAGE Publications.

Grinbaum, A., \& Groves, C. (2013). What is "responsible" about responsible innovation? Understanding the ethical issues. In R. Owen, M. Heintz, \& J. Bessant (Eds.), Responsible Innovation: Managing the Responsible Emergence of Science and Innovation in Society (pp. 119-142). Wiley.

Grunwald, A. 2011. Responsible innovation: Bringing together technology assessment, applied ethics, and STS research. Enterprise and Work Innovation Studies 7: 9-31.

Gurzawska, A. 2020. Towards responsible and sustainable supply chains-innovation, multi-stakeholder approach and governance. Philosophy of Management 19 (3). https://doi.org/10.1007/s40926-019-00114-z.

Häußermann, J.J., and F. Schroth. 2020. Aligning innovation and ethics: An approach to responsible innovation based on preference learning. Philosophy of Management 19 (3). https://doi.org/10.1007/s40926-019-00120-1.

Morgan, D.L. 2007. Paradigms lost and pragmatism regained: Methodological implications of combining qualitative and quantitative methods. Journal of Mixed Methods Research 1 (1): 48-76. https://doi. org/10.1177/2345678906292462.

Owen, R., Stilgoe, J., Macnaghten, P., Gorman, M., Fisher, E., \& Guston, D. H. (2013). A framework for responsible innovation. In R. Owen, M. Heintz, \& J. Bessant (Eds.), Responsible Innovation: Managing the Responsible Emergence of Science and Innovation in Society (pp. 27-50). Wiley.

Pellizzoni, L. 2004. Responsibility and environmental governance. Environmental Politics 13 (3): 541-565. https://doi.org/10.1080/0964401042000229034.

Ruggiu, D. 2020. Inescapable frameworks: Ethics of care, ethics of rights and the responsible research and innovation model. Philosophy of Management 19 (3). https://doi.org/10.1007/s40926-019-00119-8.

Stelzer, H. 2020. Responsible innovation and climate engineering. A Step Back to Technology Assessment. Philosophy of Management 19 (3). https://doi.org/10.1007/s40926-020-00127-z.

Stilgoe, J., R. Owen, and P. Macnaghten. 2013. Developing a framework for responsible innovation. Research Policy 42 (9): 1568-1580. https://doi.org/10.1016/j.respol.2013.05.008.

Sutcliffe, H. (2011). A report on responsible research \& innovation. http://www.matterforall.org/pdf/RRI-Report2.pdf

Timmermans, J., and V. Blok. 2018. A critical hermeneutic reflection on the paradigm-level assumptions underlying responsible innovation. Synthese: 1-32. https://doi.org/10.1007/s11229-018-1839-z.

Timmermans, J., V. Blok, R. Braun, R. Wesselink, and R. Øjvind Nielsen. 2020. Social labs as an inclusive methodology to implement and study social change: The case of responsible research and innovation. Journal of Responsible Innovation. https://doi.org/10.1080/23299460.2020.1787751.

van den Hoven, J., Doorn, N., Swierstra, T., Koops, B.-J., \& Romijn, H. (Eds.). (2014). Responsible innovation 1: Innovative solutions for global issues. Springer.

Von Schomberg, R. (2013). A vision of responsible research and innovation. In R. Owen, M. Heintz, \& J. Bessant (Eds.), Responsible Innovation: Managing the Responsible Emergence of Science and Innovation in Society (pp. 51-74). Wiley.

Publisher's Note Springer Nature remains neutral with regard to jurisdictional claims in published maps and institutional affiliations.

Job Timmermans is Associate Professor Business Ethics at the Faculty of Military Sciences of the Netherlands Defense Academy (the Netherlands). He is a member of the editorial board of Philosophy of Management. His interests cover the philosophical and sociological issues arising from the intersections of ethics, integrity and compliance within organizations. Previously, he has worked within several projects on Responsible Research Innovation (RRI) at Wageningen University (the Netherlands), De Montfort University (UK), and Delft University of Technology (the Netherlands). 